\title{
The Research Progress for Extraction Methods of Effective Ingredients from Sour Cherries
}

\author{
JIA Chao Shuang, WU Peng*, LI Xiang Yang* \\ Shandong Agricultural University, China \\ Email: wupengguai@163.com; xiangyang_1@163.com
}

\begin{abstract}
In this review, the procyanidins, anthocyanins and other bioactive components of sour cherries, as well as their extraction methods are described. The study emphasizes the recent progress of extractive technique, such as solvent extraction, cellulase extraction, ultrasonic extraction, microwave extraction, acidic ethanol extraction, etc. The future direction of extraction methods, as well as trends for the diversification of cherry extracts for future studies is also discussed.
\end{abstract}

Keywords: Sour cherry; ingredient; extract; research.

\section{Introduction}

Sour cherry, sometimes called tart cherry, is a species of genus prunus economic tress to Europe, North America and Asia. Researchers have reported that sour cherry contains significant amount of quercetin, flavonoids, procyanidins, anthocyanins and vitamins. The consumption of foodstuffs with a high number of active ingredients has a positive impact on human health, such as anti-inflammatory, anti-aging, anticancer, anti-diabetic, anti-obese, lower blood, improve sleep, antibacterial properties and capacity to relieve the stress and enhance the body immunity [1-2].

The cultivation of sour cherry in Croatia has occurred for centuries, mainly for food and medicine, but also as an ornamental plant. The extract from the cherry is also used in Europe for cosmetic purposes, which is claimed to exert a favorable action on the human complexion. Although the economic importance of sour cherry has been acknowledged by many researchers, current practices for value addition are very limited. In this context, the aim of this paper is to provide a comprehensive overview of research progress extracted methods for active ingredients of sour cherries, as this fruit and its active ingredients may be considered as important nutritional supplements.

Nowadays consumers are more and more aware of the health benefits connected with consuming food containing bioactive substances. The study is focused on the following research status of sour cherry effective components extraction methods, comparing the advantages and disadvantages of various methods and analyzing the future direction of extraction methods to better guide the development and utilization of sour cherries.

\section{The Extraction of Procyanidins}

Procyanidins are by far the most abundant in fruits and vegetables, as such, it is present in considerable amounts in the human diet. Currently, the plant extraction, chemical synthesis and biosynthesis techniques as well as extraction methods are used to extract procyanidins, and one of the most economic and safe ways is plant extraction [3]. The present study is concerned with the characterization of procyanidins including its properties and composition. Organic solvent extraction as a traditional method is used to extract procyanidins from plants, with long extraction time and complex process, low extraction rate of defects. For instance, ultrasonic assisted extraction, microwave assisted extraction, supercritical $\mathrm{CO}_{2}$ extraction and enzymatic hydrolysis technology, etc. are gradually applied to the extraction of procyanidins [4]. It was reported that procyanidins had been found in high concentrations in sour cherry. While the extracting method of cherry procyanidins has been rarely reported (only organic solvent extraction and ultrasonic assisted extraction), this suggests that understanding extraction method of procyanidins is important for the development of sour cherry. 


\subsection{Organic Solvent Extraction}

At present, organic solvent extraction is widely used to extract procyanidins in cherry [5]. Gao et al. [6] extracted procyanidins of the cherry, for the optimization of the microwave assisted sample preparation different organic solvents of reagents were tested, including ethyl acetate, ethyl alcohol, petroleum ether, etc. Using the different organic solvents the extraction yield was generally acceptable except for petroleum ether, ethyl acetate leading to the lowest extraction yield. The best extraction effects were obtained by performing the extraction using ethanol solution, thus ethanol was chosen for further experiment[4-8]. Liu et al. [2] discovered the methanol and ethanol were shown to be applicable to procyanidins extraction from sour cherry fruit when the concentration of the organic solvent was $70 \%$. But methanol has some obvious drawbacks, including the fact that contaminate the environment and high toxicity, and generally not as extraction solvent. Liu et al. chose the ethyl acetate and petroleum ether as extractant, organic solvent extraction method was validated and optimized for the determination of selected elements in sour cherry fruit. The optimized condition for extraction of organic solvent to extract procyanidins was determined as follows: $70 \%$ ethanol concentration, extraction temperature $60^{\circ} \mathrm{C}$, solid to liquid ratio of $1: 4$, extraction time was $3 \mathrm{~h}$, at this time the extraction rate was $0.38 \%$. These conditions gave maximum extraction yield with sour cherries varieties. In recent years, owing to organic solvents defect of long extraction time and low efficiency, extensive efforts were made to develop more reliable modern high extraction technology of procyanidins extraction [4].

\section{$2.2 \quad$ Ultrasonic Assisted Extraction}

Using ultrasound in the pretreatment stage and the final drying process, on one hand, is considered as a good way of enhancing mass transfer, on the other hand, can improve the extraction yield. Various stress factors, like temperature, time, power, solid-liquid ratio and extraction solvent etc. result in extraction rate decline [8]. Geng et al. [7] indicated the effect of extracting procyanidins in cherry during the processing stage, ultrasonic assisted extraction had a negative influence. The results proved that procyanidins had been found in high concentrations in cherry leaves. Further to determine the optimum process conditions of ultrasonic assisted extraction of procyanidins as follows: $70 \%$ methyl alcohol as extractant, ratio of material to liquid 1:30, extraction temperature $50^{\circ} \mathrm{C}$, low frequency and extraction time was 20 minutes, at this time the extraction rate was 5.17\%. Yang et al. [9] proved ultrasonic assisted extraction was applicable to extract procyanidins from cherry. For the optimization of the procyanidins preparation four extraction factors were tested, including ratio of material to liquid, extraction time, the concentration of ethanol and bath temperature. The main influencing factor of performing the extraction is tatio of material to liquid. The best extract conditions were optimized: $70 \%$ ethanol concentration, extraction temperature $50^{\circ} \mathrm{C}$, solid to liquid ratio of 1:8, extraction time was 5 minutes, at this time was the best extraction effect. The ultrasonic is particularly attractive as a versatile extract machine capable of extraction from many various parameters so that demonstration of its versatility beyond cherries is highly desirable [4].

\subsection{Microwave Assisted Extraction}

For the past few years, investigator proved practicable to extract procyanidins separation with microwave assisted extraction. Generally, microwave assisted extraction, with high extraction rate, simple operation, less by-products, strong penetrating power, has been replacing conventional methods, such as Soxhlet [10-11]. It has been reported that the microwave assisted extraction is practicable to grape seed to achieve procyanidins, but the actions of microwave are yet to be elucidated for procyanidins of the cherry reported. Lv et al.[10] used water as extractant, microwave assisted extraction method was validated and optimized for the determination of selected elements in grape seeds when extracted procyanidins. The experimental results show that: ratio of material to liquid 1:9, power $500 \mathrm{~W}$, time $15 \mathrm{~min}$, at this time the extraction rate was $38 \%$. And prove that this method is superior to the traditional extraction methods. Li et al.[12] chose ethyl alcohol as extractant, microwave assisted extraction method was validated and optimized for the determination of selected elements in grape seeds when extracted procyanidins. The influence factors of extraction rate were analyzed by single factor experiment. The optimized condition was determined as follows: $70 \%$ ethanol concentration, ratio of material to liquid 1:11, extraction $10 \mathrm{~s}$, extraction temperature $50^{\circ} \mathrm{C}$ and time was 30 minutes. 


\subsection{High Supercritical Fluid Extraction}

High supercritical fluid extraction is a new extraction technique, with recycled solvent, strong selectivity, low temperature, non-toxic pollution-free realizing the true sense of green environment protection [13-14]. The main advantages of high supercritical fluid extraction are retained the activity of procyanidins extracted from grape seeds. Therefore, making of procyanidins capsules are extremely popular in the field of natural plant medicine in the United States [13]. Ye et al.[14] chose grape seeds as raw material, supercritical $\mathrm{CO}_{2}$ extraction method was validated and optimized for the determination of selected elements under normal temperatures and pressures when extracted procyanidins. The results proved that in the process of extraction using ethanol or methanol as modifier, the conditions gave maximum extraction yield. In recent years, some review summarized extraction rate has been improved by combing supercritical $\mathrm{CO}_{2}$ extraction and other extraction technology. Jiang et al. [15] first used the method of supercritical $\mathrm{CO}_{2}$ in the pressure was $35 \mathrm{MPa}$, temperature $35^{\circ} \mathrm{C}$ and extraction time 130 minutes to skim of larch bark, after using enzymatic hydrolysis to extract procyanidins, at this time the extraction rate was $7.36 \%$. Now, using of procyanidins made into capsule health food has been popular in home and abroad. In recent years, procyanidins were found in high concentrations in sour cherry. However, high supercritical fluid of actions is yet to be elucidated for procyanidins of sour cherry.

\subsection{Enzyme Extraction}

Enzymatic removal of protein was an effective alternative for the common methods. Thus, it was widely used in the extraction of efficient components from plants. Owing to a great diversity of structures that enzyme plays an important role in the process of destroying the cell walls, it requires pectinase and cellulose enzyme treatment for extraction of active ingredients from plant cell walls [16-17]. A few other reports suggest that sour cherries proved difficult to procyanidins, requiring both low feed rates and extensive enzyme digestion for extraction. Therefore, procyanidins of sour cherries are extracted by enzyme, which has never been taken into account. Qin et al. [17] proved practicable to extract rapeseed skin to achieve procyanidins separation with enzymatic. The experimental results show that: particle size 90, add $35 \mathrm{u} / \mathrm{g}$ of cellulose enzyme, extraction time $100 \mathrm{~min}$, at this time the extraction rate could be up to the highest. Chen et al. [18] proved practicable to extract grape skin residue to achieve procyanidins separation with enzymatic, the optimized condition was determined as follows: $0.4 \%$ cellulose enzyme, $0.8 \%$ pectinase enzyme, extraction temperature $70^{\circ} \mathrm{C}$ and time was 90 minutes, at this time the extraction content was $11.08 \mathrm{mg} / \mathrm{g}$.

\section{The Extraction of Anthocyanins}

The content up to $312 \mathrm{mg} / 100 \mathrm{~g}$ of total phenolic in sour cherry, and sweet cherry only contains $92 \sim 147 \mathrm{mg}$ $/ 100$ g. Anthocyanins are found in high concentrations in sour cherries, the reported data show that its content is more than the orange juice and chocolate. Some indications from antioxidant have been validated by pharmacological activities of anthocyanins and its extracts. The available document showed that anthocyanins are a potential source for treatment of hyperlipidemia, cancer, gastrointestinal disorders, diabetes and obesity. For this reason, the food industry is highly interested in fruits and vegetables with high content of bioactive anthocyanins to manufacture food supplements [19-21]. The anthocyanins may occur in plant tissues combined with proteins, sugars and built polymerized derivatives, making the extraction process difficult. In addition, extraction is also affected by many other factors, such as time of extraction, temperature, $\mathrm{pH}$, solvent composition, particle size and solid-to-liquid ratio. Normally, anthocyanins extraction is a solvent and time consuming process with low extraction efficiency, and long time of process is especially critical when it is present in sample, because long exposure to heat can cause their degradation and decrease the antioxidant activity of the extracts [22]. In recent years, high-tech, faster and more automatic techniques have been replacing the conventional methods.

\subsection{Acidic Ethanol Extraction}

Acidic ethanol extraction has the characteristics of simple operation, low experimental conditions, etc. Xiao et al. [21] proved acidic ethanol extraction method was validated and optimized for the determination 
of selected elements in cherry by single factor experiment. The optimized condition for extracting anthocyanins was determined as follows: $80 \%$ ethanol concentration, extraction temperature $30^{\circ} \mathrm{C}$, solid to liquid ratio of 1:7, extraction time was $3 \mathrm{~h}$ and extracted again, at this time the extraction capacity was $26.01 \mathrm{mg} / 100 \mathrm{~g}$. Li et al.[23] proved ethanol as extractant was validated and optimized for the determination of selected elements in sweet cherry. The optimized condition for extracting anthocyanins was determined as follows: $95 \%$ ethanol concentration, solid to liquid ratio of 1:2, extraction time was $20 \mathrm{~h}$, concentrated temperature was $30^{\circ} \mathrm{C}$ and refined by $\mathrm{C}_{18}$ column. Fu et al. [24] extracted pigment in Nanking cherry by acidic ethanol extraction. The experimental results show that: hydrochloric acid to ethanol ratio of $1: 4$, solid to liquid ratio of $1: 10$, extraction temperature was $60^{\circ} \mathrm{C}$, extraction of $1 \mathrm{~h}$ after filtering, at this time the extraction rate could be up to the highest. Shen et al. [25] chose cherry as raw material and the optimized condition was determined as follows: solid to liquid ratio of $1: 2,70 \%$ ethanol concentration, extraction temperature $60^{\circ} \mathrm{C}$, extraction time was 150 minutes and extracted again, at this time was the best extraction effect.

\subsection{Enzyme Extraction}

In recent years, as one of the biocatalyst, enzyme has excellent properties of high selectivity and specificity, activity, and moderate reaction conditions, etc. Owing to their attractive characteristics, enzyme is often used to extract the effective components in the plant [26]. Zhao et al. [27] extracted anthocyanins of purple sweet potato, for the optimization of the enzyme assisted sample preparation two different enzymes were tested, including pectinase and cellulose enzyme. The best extraction effects were obtained by performing the extraction using pectinase. The best extraction condition was as follows: ratio of material to liquid 1:60, add $0.5 \mathrm{~g} / \mathrm{g}$ of pectinase, extraction temperature $40^{\circ} \mathrm{C}, \mathrm{pH}$ was 6.0 , extraction time was $2 \mathrm{~h}$, at this time the extraction content was $28.6 \mathrm{mg} / 100 \mathrm{~g}$. Owing to its safe and non-toxic, enzyme extraction is often used as food processing [28].

\subsection{Ultrasonic Assisted Extraction}

Ultrasonic assisted extraction while in the process of extraction using organic solvent and can pollute the environment, as a supplementary method that it has excellent characteristics of high extraction efficiency, extraction speed and solubilizing, etc. Therefore, ultrasonic assisted extraction has been more commonly used for anthocyanins extraction [29]. Sun et al. [30] proved ultrasonic assisted extraction method was validated and optimized for the determination of selected elements in cherry when extracted anthocyanins. The optimized condition for extracting anthocyanins was determined as follows: Methyl alcohol as extractant, power $100 \mathrm{~W}$, set frequency $59 \mathrm{~Hz}$, extraction temperature $25^{\circ} \mathrm{C}$, extraction time 10 minutes. Zhao et al.[31] in order to determine the optimization of the anthocyanins preparation two different extraction methods were tested, including enzymatic and ultrasonic assisted method. The best extraction effects were obtained by performing the extraction using enzyme-ultrasound combined. Proving extracted and the best process conditions show that: firstly, add $10 \mathrm{mg} / \mathrm{g}$ of cellulose enzyme, ratio of material to liquid $1: 8, \mathrm{PH}$ was 4.5 , extraction temperature $30^{\circ} \mathrm{C}$, extraction time $2 \mathrm{~h}$. Then add $8 \mathrm{mg} / \mathrm{g}$ of pectinase, ratio of material to liquid $1: 6, \mathrm{PH}$ was 4.0 , extraction temperature $50^{\circ} \mathrm{C}$, extraction time $2 \mathrm{~h}$, The last, using ultrasonic assisted extraction and ratio of material to liquid $1: 30$, extraction temperature $35^{\circ} \mathrm{C}$, power was $400 \mathrm{~W}$, extraction time 30 minutes, at this time the extraction rate was $43.04 \%$.

\subsection{Fermentation Extraction}

At present, fermentation as a new kind of extraction in extracting anthocyanins, it has been used for the extraction of anthocyanins. Fermentation extraction could be extracted more speedily with higher extraction yield, high utilization rate of raw materials, low production cost compared with traditional extraction [31]. Han et al. [32] proved fermentation extraction method was validated and optimized for the determination of selected elements in purple sweet potato when extracted anthocyanins. The optimized condition for extracting anthocyanins was determined as follows: add $10 \%$ yeast, $\mathrm{PH}$ was 3.0, extraction temperature $27^{\circ} \mathrm{C}$, extraction time $72 \mathrm{~h}$, at this time the extraction content was $66.6 \mu \mathrm{g} / \mathrm{ml}$. Lu et al. [33] chose blackberry as raw material, for the optimization of the anthocyanins preparation three different extraction methods were tested, including fermentation extraction, acidic ethanol extraction, enzyme 
digestion-citric acid water. The best recoveries were obtained by performing the extraction using fermentation. Zhao et al.[34] chose purple highland barley as raw material, lactobacillus fermentation method was validated and optimized for the determination of selected elements when extracted anthocyanins. While fermentation extracted anthocyanins, has never been taken into account.

\section{The Extraction of Quercetin}

The reported data reveal that quercetin is a source for treatment of arthritis, cancer and inflammatory, etc. [35-36]. It has been reported, the main method of extraction of quercetin such as: hot water refluxing extraction, ultrasonic assisted extraction, microwave assisted extraction method, impregnation method and adsorption method, etc. [37].

\subsection{Ultrasonic Extraction with Ethanol Refluxing Extraction}

Ultrasonic extraction with ethanol refluxing extraction is commonly used in the extraction of quercetin. On the one hand, ultrasonic extraction method is the use of ultrasonic break the cell wall in a short period of time, while its withdrawal rate is not high. On the other hand, although ethanol refluxing extraction required high temperature and time consuming, the quercetin extraction yield was slightly higher than the ultrasonic extraction [37]. Wang et al.[38] in order to determine the optimization of the quercetin preparation two different extraction methods were tested, including ethanol refluxing extraction and ultrasonic extraction. The best recoveries were obtained by performing the extraction using ethanol refluxing extraction, thus ethanol refluxing extraction was chosen for further experiments. The best conditions for ethanol refluxing extraction method were confirmed: hydrochloric acid to ethanol ratio of 1:10, extraction time 60 minutes and ethyl acetate extraction, at this time having the best extraction effect. Yang et al.[39] chose larch as raw material, for the optimization of the quercetin preparation three different extraction methods were tested, including ultrasonic extraction, microwave extraction and reflux extraction methods. The results indicated that the best recoveries were obtained by performing the extraction using heating temperature, thus using the different extraction methods obtained extraction yield were generally acceptable except for ultrasonic extraction. The best extract conditions were optimized: $60 \%$ ethanol concentration, solid to liquid ratio of $1: 12$, power $700 \mathrm{~W}$, extraction time was 10 minutes and for extracting twice.

\subsection{Maceration Method with Alkali-solution Acid Extraction and Acid-isolation}

Although Maceration method is simple, convenient, safe and low poisonous, it is still lower than that of alkali-solution acid extraction and acid-isolation [40]. Alkali-solution acid extraction and acid-isolation has some advantages for production of low cost, simple operation, low equipment requirement, etc. [41]. Shi et al. [42] in order to determine the optimization of the quercetin preparation three different extraction methods were tested, including alkali-solution acid extraction and acid-isolation, ethyl alcohol reflux and maceration method. The best extraction effects were obtained by performing the extraction using alkali-solution and acid-isolation extraction.

\subsection{Ultrahigh Pressure Extraction}

Ultrahigh pressure extraction is the basic principle of using under the status of the 100 1000 MP hydrostatic force for material liquid, the cells inside and outside pressure balance after rapid decompression and use a sudden increase of pressure difference to make the effective composition of cells were transferred to the outside of the cells, so as to extract effective components [43-44]. Sun et al. [43] extracted quercetin of the sweet grass, for the optimization of the ultrahigh pressure extraction method different extraction factors were tested, including the ratio of material to solvent, extracting time, temperature and times of extracting etc. The optimized condition was determined as follows: hydrochloric acid to methyl alcohol ratio of 1:3, solid to liquid ratio of 40:1, pressure $200 \mathrm{MP}$, extraction time was 2 minutes. Fan et al. [45] extracted quercetin in honeysuckle by ultra-high pressure. The best extract conditions were optimized: $60 \%$ methyl alcohol concentration, solid to liquid ratio of 1:30, pressure $400 \mathrm{MP}$, extraction time was 3 minutes, at this time the extraction content was $57.62 \mathrm{mg} / \mathrm{g}$. Ultrahigh pressure extraction demonstrates 
many advantages such as short extraction time and high extraction efficiency, etc. which is used in the extraction of effective components. However, in most of these studies only the traditional extraction, while the knowledge about the ultrahigh pressure extraction of quercetin is very limited.

\section{The Extraction of Flavonoids}

Flavonoids are considered highly bioactive substances with very low toxicity, which makes them good therapeutic candidates. The flavonoids biosynthesis pathway is one of the most studied in plants. In plants, flavonoids act against various biological and abiological stresses such as physical and radical damage, microbial infections, and ultraviolet radiation. In humans, flavonoids enter the body through consumption of plant-derived foods and play crucial roles in preventing the onset of various illnesses. Flavonoids are found in high concentrations in cherry leaves, some indications from antioxidant have been validated by pharmacological activities of the cherry leaves and its extracts. The study has shown that flavonoids are a potential source for treatment of cancer, diabetes and gastrointestinal disorders and capacity to relieve the stress and strengthen the immune system [46-47]. These features comply with the most recent therapeutic strategy for lifestyle related diseases, which require the modulation of several therapeutic goals at once to receive both functional rehabilitation and injury reduction. High consumption of flavonoids, such as, has been recently associated with reduced incidence of cancer, cardiovascular disease and risk of all-cause in human being.

The reported methods for extracting active flavonoids include water extraction, ultrasonic assisted extraction, supercritical $\mathrm{CO}_{2}$ extraction, ethanol refluxing extraction, organic solvent extraction, microwave assisted extraction, ultrahigh pressure extraction, etc. [48].

\subsection{Water Extraction}

Water extraction can't efficiently extract flavonoids and the extraction technique of flavonoids should be improved to reduce the industrial waste. Water extraction is usually combined with other methods [48]. Zhu et al.[49] in order to determine the optimization of the flavonoids preparation four different extraction methods were tested, including water quenching extraction, ultrasonic water extraction, alkaline water quenching extraction and water refluxing extraction. The best recoveries were obtained by performing the extraction using water refluxing extraction, thus water refluxing extraction was chosen for further experiments. The optimized condition was determined by water refluxing extraction as follows: solid to liquid ratio of $1: 16$, extraction temperature $90^{\circ} \mathrm{C}$, extraction time $1 \mathrm{~h}$ and extraction of three times. Zhou et al. [50] extracted flavonoids of hawthorn leaf, for the optimization of the flavonoids preparation two different extraction methods were tested, including ultrasonic water extraction and water extraction. The best recoveries were obtained by performing the extraction using ultrasonic water extraction, thus it was chosen for further experiments. The experimental results show that: ratio of material to liquid 1:30, extraction temperature $80^{\circ} \mathrm{C}$, extraction time was 40 minutes, at this time the extraction rate was $86.02 \%$. Cao et al. [51] chose hawthorn leaf as sample, for the optimization of the flavonoids preparation two different extraction methods were tested, including microwave-assisted extraction and traditional water extraction method. The results indicated that the best recoveries were obtained by microwave-assisted extraction with the advantage of higher extraction rate, less extraction time. The optimized condition was determined by microwave-assisted extraction as follows: solid to liquid ratio of 1:30, power was 360W, extraction time was 3 minutes, at this time the extraction rate was $1.21 \%$. Water extraction combined with other extraction technology, which can greatly improve the extraction yield of flavonoids. The future, it should be applied in the extraction of total flavonoids of cherry.

\subsection{Organic Solvent Extraction}

The pathway of flavonoids biosynthesis is one of the most studied in plants and the traditional organic solvent extraction methods involved are well characterized. Jiang et al. [52] proved practicable to extract cherry leaves to achieve flavonoids separation with organic solvent extraction and had no destructive effect on the other components. Jiang et al. [53] used ethanol as extracting agent and determined the best extraction technology conditions were: water to ethyl alcohol ratio of $7: 3$, extraction temperature $70^{\circ} \mathrm{C}$, 
extraction time 1h, at this time the extraction rate was $2.0046 \%$. Wang et al. [54] extracted flavonoids from cherry by ethanol in organic solvent extraction method. The optimized condition for extraction of organic solvent to extract flavonoids was determined as follows: $75 \%$ ethanol concentration, extraction temperature $70^{\circ} \mathrm{C}$, solid to liquid ratio of 1:40, extraction time was $2 \mathrm{~h}$, at this time the highest extraction rate. Zhang et al. [55] determined optimize parameter of extraction art. The experimental results show that: $65 \%$ ethanol concentration, extraction temperature $65^{\circ} \mathrm{C}$, solid to liquid ratio of $1: 32$, extraction time was $2 \mathrm{~h}$, at this time the extraction rate was $0.856 \%$.

\subsection{Supercritical $\mathrm{CO}_{2}$ Extraction and Ultrasonic Assisted Extraction}

Compared with traditional solvent extraction, the method of supercritical $\mathrm{CO}_{2}$ extraction has the advantages of short extraction time, high extraction efficiency and no poisonous waste etc. Zhang et al. [56] extracted flavonoids of cherry leaves, for the optimization of the supercritical $\mathrm{CO}_{2}$ extraction sample preparation different the extracting factors were tested, including extraction pressure, extraction time and extraction temperature. Determined the optimum experiment conditions of extraction of flavonoids are as follows: ethanol as extractant, extraction temperature $45{ }^{\circ} \mathrm{C}$, pressure $20 \mathrm{MPa}$, extraction time $3 \mathrm{~h}$, at this time the flavonoids extraction yield of $0.90 \%$. After Zhang et al. [57] extracted flavonoids from cherry leaves by ultrasonic assisted extraction, the optimized condition for extracting anthocyanins was determined as follows: ethanol as extractant, extraction temperature $50{ }^{\circ} \mathrm{C}$, power $60 \mathrm{MPa}$, extraction time $80 \mathrm{~min}$, at which time point the extraction rate was $2.32 \%$. Using the ultrasonic assisted extraction supercritical $\mathrm{CO}_{2}$ extraction obtained extraction effects were generally acceptable, however the results indicated that the supercritical $\mathrm{CO}_{2}$ extraction method gave maximum extraction yield with cherries varieties. Xeon et al. [58] extracted flavonoids of Nanking cherry, for the optimization of the ethanol ultrasonic method different extraction factors were tested, including extraction time, solid-liquid ratio and ethanol concentration etc. The optimum extraction conditions were $95 \%$ ethanol extracting with power $400 \mathrm{~W}$ ultrasonic extraction for extracting 45 minutes, at this time the extraction rate was $1.135 \%$.

\subsection{Microwave Assisted Extraction}

In recent years, microwave assisted extraction, time-saving and more automatic technique, enables uniform heated of solvent and plant matrix. Zhang et al. [59] chose blueberry leaves as raw material, for the optimization of the ethanol ultrasonic method different extraction factors were tested, including ethanol concentration, extract power, and extract temperature. The optimum extraction conditions were $64 \%$ ethanol extracting with power $456 \mathrm{~W}$ microwave extraction under $72^{\circ} \mathrm{C}$, at this time the extraction rate was $4.232 \%$. Li et al. [48] indicated the effect of extracting flavonoids in cherry leaves, during the processing stage, microwave assisted extraction had a negative influence, for the optimization of the flavonoids extraction yield main factors were tested. The optimum extraction conditions were $75 \%$ ethanol extracting with solid to liquid ratio of $1: 25$, power $300 \mathrm{~W}$ and temperature $80^{\circ} \mathrm{C}$ microwave extraction for extracting 5 minutes, at this time was the best extraction effect.

\subsection{Ethanol Refluxing Extraction}

For the past few years, ethanol refluxing extraction, due to its convenience and energy conservation, has been used to obtain flavonoids. Wang et al. [60] chose ethanol as extraction solvent for determining total flavones of cherry leaves extract. The extracting conditions were optimized: $80 \%$ ethanol concentration, solid to liquid ratio of $1: 30$, temperature $70^{\circ} \mathrm{C}$, extraction time $1.5 \mathrm{~h}$. Zhu et al. [49] chose honeysuckle as raw material, for the optimization of extracting ratio of flavonoids two extraction methods were tested, including ethanol refluxing extraction and water circumfluence. The best extraction effects were obtained by performing the extraction using ethanol refluxing extraction method. The optimum extraction conditions were $60 \%$ ethanol extracting with solid to liquid ratio of 1:60 and extracted $1.5 \mathrm{~h}$ ethanol refluxing extraction of two times.

\subsection{Ultrahigh Pressure Extraction}

Consulting lots of reference proved practicable to extract plants to achieve flavonoids separation with the 
ultrahigh pressure extraction. Sun et al. [44] proved practicable to extract hawthorn to achieve flavonoids. separation with enzymatic, for the optimization of extracting ratio of flavonoids four extraction factors were tested, including ethanol concentration, extraction time, extraction pressure and ratio of material to liquid. The best extract conditions were optimized: 90\% ethanol concentration, pressure 500MPa extraction time was 12 minutes, at this time the extraction rate was $0.0553 \%$. Li et al. [61] chose hawthorn as raw material, and ultrahigh pressure extraction method was used to extract flavonoids. The best conditions to determine extraction method were confirmed: solid to liquid ratio of 1:45, 50\% ethanol as extraction solvent, pressure $400 \mathrm{MPa}$, extraction temperature $60^{\circ} \mathrm{C}$, extraction time 3 minutes. Zond et al. [62] chose lonicera japonica leaves as raw material, for the optimization of extracting ratio of flavonoids four different extraction methods were tested, including ultrahigh pressure extraction, ultrasonic extraction, microwave extraction and alcohol soak. The results indicated that the best extraction effects were obtained by performing the extraction using ultrahigh pressure extraction with extraction yield of $13.56 \%$.However, in most of these studies only flavonoids extraction technology was studied sufficiently, while the specific antifungal mechanism of actions is yet to be elucidated for the flavonoids of the cherry reported.

\section{The Extraction of Cherry Seed Oil}

Owing to their high levels in cherry seed oil content at about 35\%, it can be used as a source of fuel [62-63]. The cherry seed oil's physical and functional properties were also evaluated in order to find value added applications for this undervalued resource. Some methods used for extracting cherry seed oil include solvent method, ultrasonic assisted method, soxhlet method, supercritical fluid method, etc.

\subsection{Solvent Extraction}

The solvent was used in the extraction of organic solvent with petroleum ether and n-hexane, acetone, ethanol and ethyl acetate, etc. N-hexane extraction was identified as the most commonly used solvent. Chen et al. [64] chose n-hexane as extraction solvent, organic solvent extraction method was validated and optimized for the determination of selected elements in sour cherry fruit, for the optimization of oil extraction rate three different extraction factors were tested, including the solvent amount, extracting time and temperature. The processing parameters of preparing cherry seed oil were $69.4^{\circ} \mathrm{C}$ of temperature, $4.1 \mathrm{~h}$ of time and $9.24 \%$ of the extraction rate. Yao et al. [65] used solvent extraction method to extracted cherry seed oil. The extract conditions were optimized: N-hexane as extraction solvent, solid to liquid ratio of 1:3, temperature $75^{\circ} \mathrm{C}$, extraction time $5 \mathrm{~h}$, at which time point the extraction yield was $10.93 \%$. Soxhlet extraction with high extraction rate, simple operation, less dosage of solvent, etc. Soxhlet method of oil extraction under the effect of solvent reflux extraction et al.[66] in order to determine the optimization of acid pulp fruit oil preparation two different extraction methods were tested, including soxhlet extraction and supercritical fluid extraction. The results indicated that application of soxhlet extraction with oil extraction rate similar to supercritical fluid extraction. Yang et al. [67] proved the cherry seed were cracked, the kernels separated and pulverized, and the oil extracted by Petroleum ether using a soxhlet apparatus. For the optimization of oil extraction rate three different extraction factors were tested, including solid-liquid ratio, extracting time and temperature. The optimized condition to extract cherry seed oil was determined as follows: petroleum ether as extraction solvent, extraction temperature $60^{\circ} \mathrm{C}$, solid to liquid ratio of 1:6, extraction time was $3 \mathrm{~h}$, at this time the oil yield from kernels was $20.18 \%$. In some literature reports this variability in oil content of the kernels is partially due to the influence of various geographic locations and conditions.

\subsection{Ultrasonic Assisted Extraction}

As a kind of optimization of oil extraction method, ultrasonic assisted extraction, shorten duration, lower cost, higher extraction yield, has been replacing conventional methods [68-69]. Wang et al. [69] extracted cherry seed oil by ultrasonic assisted extraction. Response surface experiments were used to optimize the extraction of cherry seed oil based on the results of single factor experiments. The best extract conditions were optimized: isopropyl alcohol as extraction solvent, solid to liquid ratio of 1:8, frequency $110 \mathrm{kHz}$, 
extraction temperature $40^{\circ} \mathrm{C}$, extraction time was 56 minutes, at this time the extraction content rate was $12.40 \%$. Chen et al. [68] explored the cherry seed oil was extracted by ultrasonic assisted extraction of the process. The best conditions were confirmed: n-hexane as extraction solvent, extraction temperature $40^{\circ} \mathrm{C}$, extraction time 52 minutes, at which time point the best extraction effect and the best quality of the oil was obtained. Li et al. [70] extracted the cherry kernel oil, for the optimization of the oil extraction rate preparation four different extraction methods were tested, including the ultrasonic assisted method, supercritical $\mathrm{CO}_{2}$ extraction, squeezing method and organic solvent method. The results indicated that used the ultrasonic assisted method and supercritical $\mathrm{CO}_{2}$ extraction obtained oil extraction rate were generally acceptable except for squeezing method, organic solvent method led to the lowest extraction yield. The optimum extraction conditions were petroleum ether extracting with power 300W ultrasonic extraction, solid to liquid ratio of $1: 8$ and extraction temperature $43^{\circ} \mathrm{C}$ for extracting 59 minutes.

\subsection{Supercritical $\mathrm{CO}_{2}$ Extraction}

As a kind of extraction method, supercritical $\mathrm{CO}_{2}$ extraction, shorten duration, faster and no poisonous waste, has been replacing traditional solvent extraction. Due to the biggest advantages of supercritical $\mathrm{CO}_{2}$ extraction can be operated under low temperature conditions, so that unsaturated fatty acid is not easy to oxidation decomposition, which is widely used in the oil industry [71-72]. Yang et al. [73] extracted the cherry seed oil. The best conditions for supercritical $\mathrm{CO}_{2}$ extraction were confirmed: the $\mathrm{CO}_{2}$ flow rate of 20 $\mathrm{L} / \mathrm{h}$, extraction temperature $50^{\circ} \mathrm{C}$, extraction time $2 \mathrm{~h}$, at which time point the best extraction effect was obtained. Shi et al. [74] chose cherry kernel as raw material. The main extracting factors were effected by extraction pressure, extraction temperature and extraction time. The best extract conditions were optimized: pressure $43 \mathrm{MPa}$, extraction time was 199 minutes, extraction temperature $44^{\circ} \mathrm{C}$, at this time the extraction rate was $51 \%$.

\subsection{Microwave Assisted Extraction Method}

Microwave assisted extraction principle according to the plant matrix, it contains significant amount of water which strongly assimilates microwave energy, internal super heating causes cell destruction, promoting the extraction process. Furthermore, the migration of dissolved ions, increases solvent penetration into the matrix and subsequently increases the extraction yield. Chen et al. [75] chose sea buckthorn seed as raw material, for the optimization of the oil extraction rate four different extraction factors were tested, including the extraction solvent, extraction time, extraction temperature and extraction power. The optimum extraction conditions were ethyl acetate extracting with power 500W microwave assisted extraction temperature $55^{\circ} \mathrm{C}$ for extracting 2.5 minutes. Compared with the soxhlet extraction method, the microwave assisted extraction method was time saving and more efficient. Ran et al. [76] chose cherry seed as raw material and microwave assisted method of oil extraction process was studied. The factors that affected the extraction of oil extraction rate included the ratio of material to solvent, extracting time and temperature. Through the means of single factor or orthogonal analysis, the optimized methods of synthesis were as follows: extraction temperature $50{ }^{\circ} \mathrm{C}$, solid to liquid ratio of $1: 7$, extraction time was 15 minutes. Compared with the solvent extraction and soxhlet extraction method, the microwave assisted extraction was time saving and more efficient.

\section{$7 \quad$ Summary and Future Directions}

The most common naturally active ingredients such as procyanidins, anthocyanins, quercetin and flavonoids are important in human nutrition, it also supplies the consults to the researchers on natural food antioxidant and technicians on food field. While these cherry active ingredients have been extensively studied, particularly at flavonoid, little is known about the knowledge between the animal experiments and clinical trials. Bioactive components of sour cherries are a potential source for treatment of sickness. Unfortunately, the pharmacological studies in this area are still insufficient to substantiate these preventive effects in confirmatory trials on the mass-scale clinical settings. Future studies on bioavailability, mechanisms of action, adverse effects of the extracts, pharmacokinetics and bioactive constituents as well as their effective in modern medicines. The available document showed that most of the activities of the 
extracts are due to their constituents, procyanidins, anthocyanins, quercetin, flavonoids and other iridoids, vitamins and phenolic for their antioxidant and other properties, more scholars and social workers should show concern over, and find the solution to the problems in the their development.

The need for new and useful active ingredients to provide assistance and relief in all aspects of the human condition is ever growing. In developing countries, the availability of modern extraction technique is limited, so traditional extraction techniques are still the mainstay of ingredients extraction from cherries. Some emphases on further research are indicated, such as the use of new technology about the extraction of efficient components in sour cherry. Combination with several kinds of new and high technology would be more desirable for improving the extraction effect and helping lower costs, such as the steps of extracting anthocyanins were as follows: it was extracted from cherry by ultrasonic assisted extraction, which leftovers was extracted by acidic ethanol extraction method. Owing to extraction and optimization, the effective ingredient was purified after the extraction to realize the synthesizable of extraction technology.

The researchers stressed, however, that the finding was preliminary and the laboratory research far ahead of the production. Since large-scale test of extraction method has high significance at enhanced sour cherries utilization and effective components at extraction would greatly increase its market value. Sour cherries could be used as a source of new health sources when improving nutritional properties of the world's less traditional cherry species.

Acknowledgments. This review did not receive any specific grant from funding agencies in the public, commercial, or not-for-profit sectors.

Conflict of interest. The authors declare no potential conflict of interest, including any financial interest.

\section{References}

1. CUI Xin-ying, LI Xiang-yang, KONG Xiang-yu et al. The Active Ingredients and Pharmacological Effects of Sour Cherry Fruit. [J]. Journal of Bei Hua University (Natural Science), 2007, 02:145-149.

2. LIU Yan-qiu, MENG Qing-fan, GAO Wen-tao. Technology of Extracting Procyanidins from Prunus cerasus L. [J]. Hubei Agricultural Sciences, 2014, 06:1384-1387.

3. LUO Guan-zhong. The Study of Extraction, Separation Resistance and Stability of Procyanidins [D]. Tianjin University of Science and Technology, 2006.

4. LI Chao, WANG Wei-dong. Research Progress in Extraction Methods of Procyanidins. [J]. Cooking Oil Processing, 2009, 09:145-148.

5. DAI Jing-jing, LIU Wen-jie, ZENG Fan-jun. Study on the Extract of Proanthocyanins in Low Temperature. [J]. Food Industry, 2008, 01:18-20.

6. GAO Hai-yan, ZHAO Lei, HU Xiao-song et.al. Cherry Pigment Extraction and Stability Study. [J]. The Food and Fermentation Industry, 2003, (04):54-57.

7. GENG Jing-zhang, QIN Gong-wei, ZHANG Zhi-jian. Extraction of Procyanidins from Cherries with Ultrasound. [J]. China Food Additives, 2010, 04:183-187.

8. QIN Fei, WANG Long. Research Progress in Extraction Methods of Procyanidins. [J]. Journal of Beijing Union University (Humanities and Social Sciences), 2012, 04:36-39+50.

9. YANG Qing-zhen, WANG Feng, SUN Yuan-lin. Fruit Sweet Cherry Red Pigment Extract and Stability Study [J]. Food Science.2010, (04):120-122.

10.LV Li-shuang, PAN Dao-dong. Microwave of Grape Seed Low Poly Procyanidins(OPC) 's Extraction. [J]. Food and Machinery, 2004, (06):31-32+51.

11.CEHN Yin-ru, KANG Jian, ZHAO Fu-rong. Ultrasonic Microwave Double Assisted Extraction of Grape Seed Research of Oligomeric Procyanidins[J]. China Brewing, 2012, (08):23-28.

12.LI Feng-ying, CUI Rui-jing, LI Chun-hua. The Microwave Assisted Method is Adopted in The Extraction of Grape Seed Procyanidins[J]. Food and Fermentation Industries, 2005, (01):39-42.

13.LIU Xue-mei, ZHU Feng-tao, WU Mao-yu et al. Supercritical Fluid Extraction Technology in The Application of The Fruit Resources Extracting Efficacy Components[J]. China Fruit and Vegetable, 2012, (04):39-41. 
14.YE Xiai-zhao, ZHOU LIANG, MO Qi-wu et.al. Supercritical Fluid Extraction of Grape Seed Procyanidins[J]. Resources Development and The Market, 2007, (10):868-869+892.

15.JAING Gui-quan, FANG Gui-zhen, ZHANG Zhuo-rui et.al. Supercritical CO2 Auxiliary-ultrasound Enhancement of Larch Bark Procyanidins Extraction Process Optimization[J]. Science and Technology, 2013, (18):257-261.

16.WANG Jia-ning, HAO Yu-gang, JIAN Pu et.al. Extraction Method and Research Progress of Procyanidins[J]. Shanghai Journal of Traditional Chinese Medicine, 2015, (10):94-97.

17.QIN-Yongjian, ZHANG Jia-yan, WAN Yong-yan. Cellulose Enzyme Assisted Extraction Rapeseed Skin of Procyanidins [J]. Beijing Agriculture, 2012, (24):4-6.

18.CHENYue-ying. WANG Yan-ping, SUN Rui-lin et al. Grape skin residue procyanidins enzymatic extraction process optimization and oxidation resistance[J]. Northern Horticulture, 2016, (16):129-132.

19.Amitabh. Chandra; Muraleedharan G. Nair; Amy. Iezzoni.Evaluation and characterization of the anthocyanin pigments in tart cherries (Prunus cerasus L.) [J]. Journal of Agricultural and Food Chemistry.1992, Vol.40(No.6):967-969.

20.Halvorsen BL; Carlson MH; Phillips KM; Bun SK et al. Content of redox-active compounds (i.e., antioxidants) in foods consumed in the United States[J]. The American Journal of Clinical Nutrition.2006, Vol.84(No.1) : 95-135.

21.XIOA Jun-xia, HUANG Guo-qing, CHI Yu-sen. Cherry Anthocyanins and Antioxidant Activity of Extraction. [J]. Journal of Chinese Food, 2011, 05:70-75.

22.YU Dong, CHEN Gui-xing, FANG Zhong-xiang et al. The Research Progress of Extraction - Isolation and Qualification of Anthocyanin. [J]. Food and Fermentation Industries, 2009, 03:127-133.

23.LI Yang, QIN Chuan-guang, SHANG Xiao-ya et.al. The Extraction of Sweet Cherry Pigment and Antioxidant Activity[J]. Chemical Research, 2008, (04):28-31.

24.FU Hong, YU Ze-yuan, XU Ya-qin. Cherry Red Pigment Research of Light and Heat Stability[J]. Food Science and Technology, 2004, (05):40-41+49.

25.SHEN Yuan. Cherry Fruit Nutrition and Research of Anthocyanins[D]. Nanjing Forestry University, 2014.

26.LI Jin-lin, LIU Lin-yong, TU Zong-cai et al. Purple Sweet Potato Anthocyanins of Enzymatic Extraction. [J]. Jiangxi Food Industry, 2009, 04:25-27.

27.ZHAo Xiao-dan, LI Jia. Cellulose and Pectin Enzymatic Extraction of Purple Potato Anthocyanins Process Optimization[J]. Food Science and Technology, 2015, (04):277-281.

28.ZHANG Hai-yan, WANG Yang-guang. The Extraction of Cherry Anthocyanins in Preparation. [P].Shan dong : CN104892700A, 2015-09-09.

29.HUANG Hua, LIU Xue-wen, WANG Yi. Oats Principal Component Extraction Method is Reviewed. [J]. Food Industry, 2011, 06:94-96.

30.SUN Dan, CHEN Wei-kai, HE Fei. et al. HPLC-MS/MS Method for Determination of Sweet Cherry Anthocyanins with the Composition and Content of Anthocyanins of Phenol. [J]. Food science, 1-8.

31.ZHAO Yu-hong, ZHANG Li-gang, MIAO Yu. Enzyme-Ultrasound Coupled to The Study of The Anthocyanins of The Extraction of Indigo Slag Blended[J]. Science and Technology, 2008, (08):183-185.

32.HAN Yong-bin. Purple Sweet Potato Anthocyanins Extraction Technology and Composition Analysis and Its Stability and Oxidation Resistance[D]. Nanjing Agricultural University, 2007.

33.LU Feng-bo, YUAN-Hua, LI-Wei et.al. The Blackberry Anthocyanins Pigment Extraction Method Comparison Research and Optimization[J]. Jiangsu Agricultural Sciences, 2010, (05):366-369.

34.ZHAO Hui, WAN Qiang. A Kind of Lactic Acid Bacteria Fermentation Extraction Methods of Anthocyanins in Highland Barley[P]. Tibet : CN103276026A, 2013-09-04.

35.XUE Wang-jun, LI Feng-yi. The Determination Method of Quercetin in Chinese Herbal Medicine Research. [J]. Jiangxi chemica, 2006, 04:9-14. 1

36.ZHANG Yan-jun, DAI Shi-feng, ZHAG Xin-lin et. al. Lamp Cost Determination of Quercetin Extraction Method in the Process of Improvement. [J]. Journal of institute of kunming,2014,06:39-41.

37.ZHANG Yu, SU Dan. Dihydro Quercetin Extraction Method of Comparison and Optimization. [J]. Journal of Chinese Medicine, 2015, 10:1470-1472.

38.WANG Wan-hui, HU Ji. RP-HPLC Determination of The content of Quercetin in Cherry. [J]. Spectrum laboratory, 2010, 01:112-115. 
39.YANG Lei, MA Chun-hui, HUANG Jin-ming et.al. Xing-an Dihydro Quercetin in The Llarch Extract Method of Comparison[J]. Forest Engineering, 2009, (05):6-11.

40.WU Jie, ZHOU Ben-hong. Quercetin Optimizing Extraction Conditions. [J]. Journal of Hubei college of traditional Chinese medicine, 2006, 03:25-26.

41.LIU Jin-xiang, WANG Shui-xing, FAN Qing-sheng. Alkali Soluble Acid Sinking Method of Extraction of Flavonoids from Ginkgo Biloba Leaves. [J]. Anhui agricultural science, 2008, 26:11386-11388.

42.SHI Ying, MENG Hua, LI Jia-zhu. et al. Quercetin in Yunnan Wild Cherry Extract Method of Research. [J]. Journal of Yuxi Teachers College, 2013, 08:60-63.

43.SUN Yuan-yuan. Clover Leaf Extract Method of Quercetin in Research and HPLC Determination[D]. Jilin University, 2008.

44.SUN Xie-jun, LI Xiu-xia, FENG Xiu-xia, et al. Hawthorn Flavones Ultrahigh Pressure Extraction Technology was Studied[J]. Science and Technology, 2015, (02):291-295+312.

45.FAN Li. Three Kinds of Medicinal Herbs Effective Ingredients Such as Ultrahigh Pressure Extraction of Flos Lonicerae. [D]. Shandong Agricultural University

46.JIANG Dan, HU Wen-zhong, JIANG Ai-li. Et.al. Flavonoids in the Leaves and Stems of Cherry and Cherry Seed Oil, the Research Progress of Extraction and Purification. [J]. The Food Industry Science and Technology, 2015, 17:388-391.

47.LI Chen, JIANG Zi-tao, LI Rong. High Performance Liquid Chromatography - Tandem Mass Spectrometry Technology Appraisal of Cherry Leaves Flavonoids Ingredients. [J]. Food science, 2013, 16:226-230.

48.LI Chen. Cherry Leaves Flavonoids Ingredients in the Research. [D]. Tianjin commercial university, 2013.

49.ZHU Ying, QIU De-sheng, CHEN Min et.al. Gold and Silver Mosaic Water Extraction Technology of Total Flavonoids[J]. Chinese Patent Medicine, 2007, (01):60-63.

50.ZHOU Gui, DENG Guang-hui, LIANG Da-wen. Ultrasonic Method of Hawthorn Leaf Medium Yellow Ketone Water Extraction[J]. Journal of Southwest Agricultural University (natural science edition), 2005, (05):40-42.

51.CAO Ye-xia, YIN Ai-ping, ZHANG Hai-rong. Research of Microwave Method of Water Extraction Hippophae Rhamnosides Medium Flavone[J]. Journal of Yantai Teachers College (natural science edition), 2006, (02):128-129.

52.JIANG Dong-li. Cherry Ye Zhongxin Structure Identification of Flavonoids. [D]. Jilin University, 2005.

53.JIANG Yi-hua, JIANG Xin-ling. Cherry Leaves Flavonoids Extraction Technology was Studied. [J]. China Food Additives, China Food Additives, 2006, 06:79-84.

54.WANG Li-xin. To Extract Flavonoids from The Cherry Fruit of Research[J]. Agriculture of Jilin, 2010, (09):60-61.

55.ZHANG Jing-min, LV Ling-ling, GUO Lei. Cherry Pit and Its Antioxidant Flavonoids Extraction in Sex Research[J]. China Brewing, 2010, (06):65-68.

56.ZAHNG Jie, FU Jia, JIAO Shu-qing. Research of Supercritical Carbon Dioxide Extraction of Flavonoids from Cherry Leaves. [J]. Heilongjiang Medicine and Pharmacy, 2009, 02:10-11.

57.ZHANG Jie, JIAO Shu-qing, TENG Yang, et al. Cherry Extraction Technology of Total Flavonoids in the Leaves and Study. [J]. Heilongjiang Medicine and Pharmacy, 2010, 02:13-14.

58.XIONG Wei-wei, XU Ming-jian, LIU Jian. MAO Cherry Flavonoids Ultrasonic Extraction Process Optimization[J]. Chinese Journal of Experimental Formulas of Chinese Medicine,2012, (15):29-31.

59.ZHANG Yu-xiang, QU Hui-ge, YANG Run-ya et al. The Response Surface Method to Optimize the Blueberry Leaf Microwave Extraction Technology of Flavonoids[J]. Food Science, 2010, (16):33-37.

60.WANG Yang-fang, XIU Jin-xia, ZHAO Feng. et al. Cherry Leaves Flavonoids In vitro Antioxidant Activity. [J]. Journal of Food Science and Biotechnology, 2014, 09:966-970.

61.LI Hong-wei, ZHANG Shou-qin, DOU Jian-peng et al. Ultrahigh Pressure Extraction Flavonoids in Hawthorn Leaves[J]. Jilin University Journal (liberal arts ed.),2006, (03):438-442.

62.Pawel Gomas, Inga Misina et al. Composition of bioactive compounds in kernel oils recovered from sour cherry (Prunus cerasus L.) by products: Impact of the cultivar on potential applications[J].Industrial Crops and Products, 2016, 82:44-50

63.JIANG Dan, HU Wen-zhong, JIANG Ai-li. Flavonoids in the Leaves and Stems of Cherry and Cherry Seed Oil, the Research Progress of Extraction and Purification[J]. Science and Technology, 2015, 17:388-391.

64.CHEN Qian, ZHU Chuan-he, ZHAO Li. Cherry Seed Oil Extraction technology was studied. [J]. Chinese Cereals and Oils Association, 2010, 06:76-80. 
65.YAO Hong-liang, JIANG Sheng-hui, LIU Cheng-hua et al. Cherry Kernel Oil Extraction Technology was Studied and Its Fatty Acid Composition Analysis. [J]. Cereal and Food Industry, 2012, 01:30-32.

66.LU Zhan-guo, LI Wei. Type to Extract Seed Oil Acid Berries and Composition Analysis. [J]. Journal of the Chinese Cereals and Oils Association, 2010, 12:75-77+91.

67.YANG Shou-feng, QIOA Xia, ZHENG Ya-jie. The Development and Utilization of Cherry Seed Oil. [J]. Agricultural science and technology and information, 2010, 21:57-58.

68.CHEN Qian, ZHU Chuan-he, JIN Jun. Ultrasonic Assisted Extraction Process of Cherry Seed Oil. [J]. Food and Fermentation Industries, 2009, 12:163-167.

69.WANG Ning-na, SHI Ke-xin, ZHAO Wu-qi et al. The Response Surface Method to Optimize Ultrasonic Assisted Extraction Cherry Seed Oil Technology Research. [J]. Science and Technolog, 2014, 02:230-234.

70.LI Xu-ying, SHI Ke-xin, WANG Kai-jie et al. Different extraction methods on the cherry kernel oil quality[J]. China Oils and Fats, 2016, (03):36-40.

71.WANG Yuan-fang, XIU Jin-xai, ZHAO Feng et.al. Cherry Leaves Flavonoids In vitro Antioxidant Activity[J]. Journal of Food Science and Biotechnology, 2014, 09:966-970.

72.ZHOU Liang, MO Qi-wu. The Research Progress of Supercritical Extraction of Grape Seed Procyanidins[J]. Journal of Guangdong Light Industry Professional Technology Institute, 2006, (03):27-30.

73.YANG Xiao, LUO Jing, ZHANG Guang-feng et al. Supercritical CO2 Extraction from Serration Cherry Seed Oil, and the Antioxidant Activity of Volatile Oil and Composition Analysis. [J]. Food and Fermentation Industries, 2016, 03:207-211.

74.SHI Ke-xin, ZHAO Wu-qi, GU Ru-xiang et al. Cherry Kernel Oil of Supercritical CO2 Extraction and GC-MS Analysis[J]. Chinese Cereals and Oils Association, 2016, (01):60-64+69.

75.CHEN Jin-e, WANG Xiao-ling, ZHANG Hai-rong. Research of Microwave-assisted Extraction of Seabuckthorn Seed Oil[J]. Food Research and Development, 2007, (10):80-82.

76.RAN Jun-jian, LU Kui, ZHU Yu-ying et.al. The Method of Microwave Extraction Cherry Kernel Oil [J]. Food Science, 2007, (12):146-149. 